\title{
IMAGES OF A GRANDMOTHER IN THE MOVIE “THE WAY HOME”
}

\author{
Inero Valbuena Ancho, ${ }^{1, *}$ Aljon Delmo Galang ${ }^{2}$ \\ ${ }^{1}$ Education Faculty, Philippine Normal University, Taft Avenue, Manila 1000, Philippines \\ ${ }^{2}$ Department of Education, Iba National High School, Iba, Hagonoy, Bulacan 3002, Philippines
}

\section{ARTICLE INFO}

Keywords:

Grandmother

Images

Movie

Reflection

Article History:

Received: $12 / 11 / 2019$

Accepted: 19/05/2020

Available Online:

31/05/2020

\begin{abstract}
Images, as portrayed in movies, create a deep connection to its viewers, regardless of culture, history, or social status. A movie may make or break one's idea of a personality depending on role portrayal and projection. This study showcases how Filipino viewers perceive a grandmother in the movie "The Way Home". After watching the movie, participants were asked to reflect on the image of a grandmother based on the film and compare and contrast these ideas based on their personal experience and social construction of a Filipino grandmother. This study is qualitative in nature involving content analysis of perceptions of a grandmother based on a film. As Filipinos consider living with grandmothers a very meaningful experience, participants have noted very memorable childhood experiences because of this film. The Filipino society regards that those who grow up with their grandmothers, or grandparents, in general, to be more courteous, kind, and of good values. "The Way Home" may be a Korean movie but to Filipino viewers, it is a reminder that a grandmother's unconditional love is the same affection regardless of culture, history, or social status.
\end{abstract}

2442-305X / (C) 2020 The Authors, this is open access article under the (CC-BY-NC) license (https://creativecommons.org/licenses/by-nc/4.0/), DOI: 10.19105/ojbs.v14i1.2710

\footnotetext{
* Corresponding Author:

Email address: ancho.iv@pnu.edu.ph (I. V. Ancho)
}

\section{A. Introduction}

Moviegoers watch films and eventually validate pre-existing images of the characters that appear in the story. Some images are portrayed differently, thus creating a brand new image of the characters presented. Watching movies in cinema plays a crucial role in our daily living $^{1}$ as films could reinforce a particular

\footnotetext{
${ }^{1}$ Chieko Iwashita, "Roles of Films and Television Dramas in International Tourism: The Case of Japanese Tourists to the UK," Journal of Travel \&
}

idea of a persona or destroy previously held notions then highlight new descriptive remarks about the personality being depicted. A study also recognizes the strength of media in creating an impact on people's general world view.

Generations may pass but movie watching will still be a part of people's activities: cultural, academic, or maybe for

Tourism Marketing 24, no. 2-3 (June 1, 2008): 139-51, https://doi.org/10.1080/10548400802092635. 
leisure purposes. Time spent on watching films can be considered a productive activity since it provides avenues for rest, relaxation, and even intellectual discourse. Films could also create an influence on how viewers believe and behave. ${ }^{2}$

The way people consume movie contents may have evolved, from cinemas to downloaded movie files, to online streaming, but the fact remains that films are effective media in reaching the people's consciousness.

Movies as utilized for academic purposes can be considered a good practice, especially in foreign language classes. Movies are employed for the vocabulary development of the students. ${ }^{3}$ Perspectives transmitted through various channels will eventually have long term, powerful effects on audiences. ${ }^{4}$

A related study revealed that graduate students prefer TV/video/films on Korean-related content when it comes to their language learning. ${ }^{5}$ These activities as part of self-directed learning increase understanding of the lesson

\footnotetext{
${ }^{2}$ Susannah R. Stern, 'Self-Absorbed, Dangerous, and Disengaged: What Popular Films Tell Us about Teenagers', Mass Communication and Society 8 , no. 1 (1 February 2005): 23-38, https://doi.org/10.1207/s15327825mcs0801_3.

${ }^{3}$ Adem Işcan, "Using Films in Vocabulary Teaching of Turkish as a Foreign Language," Journal of Education and Training Studies 5, no. 5 (May 2017): 27-35, https://doi.org/10.11114/jets.v5i5.2245.

4 Debra Merskin, "Reviving Lolita?: A Media Literacy Examination of Sexual Portrayals of Girls in Fashion Advertising," American Behavioral Scientist 48, no. 1 (September 2004): 119-29, https://doi.org/10.1177/0002764204267257.

${ }^{5}$ Inero V. Ancho, "Learning Korean as a Foreign Language: The Case of a Teacher Education Institution in the Philippines," Human Behavior, Development and Society 20, no. 2 (June 2019): 74-81.
}

being studied. ${ }^{6}$ Teachers of foreign language employ strategies to combat 'language anxiety' which may pose as a hindrance to learners. ${ }^{7}$ It has been noted that "professionally-oriented foreign language teaching" contributes to students' professional competence. ${ }^{8}$

In a setting where the language being studied is not spoken, movies provide the need for students to hear native speakers use the language. In the long run, lessons on culture are considered a strategy to "go beyond" language. ${ }^{9}$ Education, along with other fields such as job vacancy and business, entails second language master. ${ }^{10}$ As vocabulary words are also part of the conversation, students as movie watchers are given the idea of the genuine usage of the words that they have memorized.

\footnotetext{
${ }^{6}$ Abdul Wafi, 'Using Games to Improve Students' Active Involvement in the Learning of English Syntax at IAIN Madura: An Autonomous Learning," OKARA: Jurnal Bahasa dan Sastra 13, no. 1 (May 31, 2019): 107 , https://doi.org/10.19105/ojbs.v13i1.2256.

${ }^{7}$ David Kondo and Yang Ying Ling, "Strategies for Coping with Language Anxiety: The Case of Students of English In Japan," ELT Journal 58, no. 3 (July 2004): 258-65, https://doi.org/10.1093/elt/58.3.258.

${ }^{8}$ Marina V. Vedishenkovaa and Anna Y. Mironinab, "The Methodology of Foreign Language Integrative Teaching at the Initial Stage of Interpreter Training," International Journal of Environmental \& Science Education 11, no. 8 (2016): 1975-88, https://doi.org/10.12973/ijese.2016.571a.

9 Kimberly Anne Brooks Lewis, "Adult Learners' Perceptions of the Significance of Culture in Foreign Language Teaching and Learning," Journal of Education and Training Studies 2, no. 2 (April 2014): 9-19, https://doi.org/10.11114/jets.v2i2.250.

10 Sofia Marwati and Gusdi Sastra, "Working Memory Role on Gender towards Language Transfer: Study of Neurolinguistics," OKARA: Jurnal Bahasa dan Sastra 13, no. 2 (November 23, 2019): 181-92, https://doi.org/10.19105/ojbs.v13i2.2566.
} 
A study has argued about the advantages of letting students "hear and understand the target language correctly." 11 There is also a crucial need for foreign language teacher to possess an acceptable level of proficiency in the target culture. ${ }^{12}$ Another study concluded that media as learning resources could be tapped in developing awareness and cultural sensitivity among students. ${ }^{13}$ It is also imperative to consider the preferences and styles of students who study a foreign language. ${ }^{14}$

The environmental setting of the movie, being a cultural product of the country where the foreign language is spoken, also boasts interesting artifacts. These vivid details compliment foreign language learning and validate the fact that learning a new language is not confined to vocabulary and grammatical rules alone; culture and society also play crucial roles in its success. Eventually, media shaped and built the consciousness particular phenomenon understanding, ${ }^{15}$ and plays a crucial role

11 Yasemin Darancık, "Students' Views on Language Skills in Foreign Language Teaching," International Education Studies 11, no. 7 (2018) 166-78, https://doi.org/10.5539/ies.v11n7p166.

12 Hakan Demiroz and Savas Yesilyurt, "Effective Foreign Language Teaching: Perceptions of Prospective English Language Teachers," Universal Journal of Educational Research 3, no. 11 (2015): 862-70 https://doi.org/10.13189/ujer.2015.031112.

${ }^{13}$ Ancho, "Learning Korean as a Foreign Language: The Case of a Teacher Education Institution in the Philippines," 81.

${ }^{14}$ Reza Vaseghi, Effatdokht Ramezani, and Reza Gholami, "Language Learning Style Preference: A Theoretical and Empirical Study," Advances in Asian Social Sciences 2, no. 2 (2012): 441-51.

${ }^{15}$ Gina Nanda Utama and Rosaria Mita Amalia, "Negative Representation of Assad's Regime in CNN Online Articles," OKARA: Jurnal Bahasa dan in the viewers' socialization aspects. ${ }^{16}$

In a study by Lauzen \& Dozier, ${ }^{17}$ it was stated that the depiction of a persona echoes political and social views. Films provide opportunities for viewers to discover astonishing worlds and encounter wild and colorful characters. ${ }^{18}$ This study is an attempt to uncover how Filipino students view the image of a grandmother. While these students may have their depiction of a grandmother based on their personal experiences, the process of weaving these ideas are made after they have watched the 2002 Korean film The Way Home (Jibeuro).

The Way Home narrates the story of a mute grandmother and her city-born grandson named Sangwoo. In the movie, the grandmother portrays her life as a loving, selfless old woman, despite Sangwoo's disrespectful attitude. She endured every pain and continues to treat Sangwoo as her very special grandson. Turn of events happens when the grandson eventually realizes the sacrifices her grandmother did for him. Days passed, Sangwoo gradually learned to show love towards her grandmother. The film was chosen because of its very positive review among Korean and international viewers.

Sastra 13, no. 1 (May 31, 2019): 1-16, https://doi.org/10.19105/ojbs.v13i1.2140.

${ }^{16}$ Mina Lee, Won Oh, and Kyung Lee, "North Korean Refugee Women's Consumption of South Korean TV Dramas and Movies," Asian Women 29 (December 1, 2013): 1-23.

${ }^{17}$ Martha Lauzen and David Dozier, "Maintaining the Double Standard: Portrayals of Age and Gender in Popular Films," Sex Roles 52 (April 1, 2005): 437-46, https://doi.org/10.1007/s11199-005-3710-1. 18 Julia Boyd, "An Examination of Native Americans in Film and Rise of Native Filmmakers," The Elon Journal of Undergraduate Research in Communication 6, no. 1 (October 2014): 105-13. 
Box office figures also reveal favorable cinema admissions.

Two problems were tackled in this study. The first is how viewers react to a film that tackles the life of someone who has become a part of their life, though presented in the context of a different culture, language, and environment. The second is how is the presentation of a Korean grandmother in a film strengthens or eventually create a variety of images in the minds of Filipino viewers. These inquiries were explored in this study with the end goal of highlighting the perception of a grandmother based on the movie The Way Home, by employing a movie as an element for the "classroom to be more focused on language communication" as a dynamic pedagogical approach. ${ }^{19}$

\section{B. Method}

This study is qualitative in nature involving content analysis of perceptions of a grandmother based on a film. This paper presents the images of a grandmother, highlighting similarities and differences, particularly focusing on one's personal experiences. Participants were selected through purposive sampling.

Participants watched the Korean film The Way Home, with English subtitles. The researcher maximized the benefits of technology as it is also an aspect that boosts student motivation. ${ }^{20}$ It has been

${ }^{19}$ Kaukab Abid Azhar, Nayab lqbal, and Mahvish Sohaib Khan, 'Do I Talk Too Much in Class? A Quantitative Analysis of ESL Classroom Interaction', OKARA: Jurnal Bahasa dan Sastra 13, no. 2 (23 November 2019): 193-202, https://doi.org/10.19105/ojbs.v13i2.2491.

20 Lindy Woodrow, "Motivation in Language Learning," in Essential Competencies for English- noted that these tools make the experience a fulfilling and exciting one. ${ }^{21}$ Then, the participants were asked to develop a reflection paper about the film, with the central questions. They were asked about what images of a grandmother were presented in the movie, and the second, based on their personal experiences, how are those images similar or different to Filipino grandmothers. The researcher employed recently published studies to serve as a guide in analyzing the responses. Themes were crafted and identified pertaining to the main inquiry of the research.

Participants of this study were students of the Korean language course in a graduate program of a teacher education institution based in the City of Manila, Philippines. They belong to doctorate programs in the education sciences, behavioral and social sciences, arts and languages, and science and mathematics education, respectively. They are required to take 6 units of a foreign language as mandated by the Commission of Higher Education as a requirement for graduation. ${ }^{22}$ Essential data of the study were from 22 reflection outputs of graduate students.

Medium University Teaching, by R. Breeze and C. Sancho, vol. 27, Educational Linguistics, 2017, 235-48, https://link.springer.com/ content/pdf/10.1007\%2F978-3-319-40956-6_16.pdf. 21 Halil Küçükler and Abdullah Kodal, "Foreign Language Teaching in Over-Crowded Classes," English Language Teaching 12, no. 1 (2019): 16975, https://doi.org/10.5539/elt.v12n1p169.

${ }^{22}$ Commission on Higher Education of Office of the Resident of the Republic of the Philippines, "Implementing Guidelines in the Inclusion of Foreign Language as Electives, in the Curricula of Higher Education Programs," 23 Ched Memorandum Order (2010). 


\section{Results}

This section presents analysis of reflection outputs of graduate students. Through the examination of the data emerged three themes in relation to the images of a grandmother as presented in the movie: unconditional, never-ending spring of love, a brand of fighting spirit, and a unique sense of style. These three representations capture a grandmother's image as reported by graduate students.

\section{Unconditional, Never-ending Spring of Love}

Indeed, it is undeniable that grandmothers' love for their families especially for their grandchildren is celebrated across societies in the world. It is reflected in all means of modern human expressions such as in films. Movies, being a piece of Man's life, provide a glimpse of how individuals portray and perceive a grandmother universally and uniquely.

The presence of a grandmother in one's life means having a caring person ready to love unconditionally. They are epitomes of altruism and spring of love extending from their children to their grandchildren. Their love echoes that of a mother or a father, sometimes beyond parental affection. A day with grandmother highlights round-the-clock and unending love offered to their loved ones. These concepts are identified in the film's main character.

As they contemplate, graduate students discern selfless and unconditional love from the character, made special by her traits:
"The images portrayed in the movie are selfless: giving unconditional love to her child and grandchild: industrious and hardworking, dependable, compassionate, a great cook, and a fountain of care and understanding." (R1)

It is by nature that individuals develop a sense of responsibility when others are depending on them. Though parents are the familial custodians especially of their children, grandparents still selflessly help in raising their grandchildren especially in times of apprehensions. Love is an innate and circumstance-based force that drives one to do his or her job even if it is not his or her responsibility. This force portrayed in the movie is possessed by grandparents as perceived by the participants. Moreover, the grandmother's act is perceived to be as an example of selfless concern and love: putting forward the needs of your loved once before yours.

"The grandmother expresses her love towards her grandson by giving everything she has to him, even to the point of prioritizing the needs of her grandson." (R3)

"A Filipino grandmother is also selfless giving so much unconditional love to her grandchildren." (R1)

Altruism is intertwined with love in many ways and love, the same as the former, is expressed in diversity. However, its expression must not be measured alone through verbal hermeneutics. It is not a mere figure of discourse, but a matter of unconditional action. The grandmother putting her grandson before herself is an exemplification of selfless and unconditional love. 
"The love she expressed to her grandson is selfless. She loves him more than words; the kind of love which is unconditional." (R6)

Writers take an episode of reality from their first-hand and/or second-hand experiences to create a movie script that viewers can relate to. Moreover, movie, being an extension and interpretation of a text taken from real-life situations, reflects society's experiential commonalities. Due to this reason, the participants can relate their dealings with their grandparents to the main character's portrayal. As implied, some responses focus on the students' personal experiences with their grandmothers. These statements are evident in the daily life of a kid living with a grandmother. From the succeeding responses, grandmothers are seen as models of sacrifices.

"I can say that grandparents are the best. I for one grew up living with my grandma and surely she made sure I was taken care of. She always made sure that I ate properly or wellgroomed and even to the point of giving up her comforts. They may not be perfect but they always try harder to give what they always think is the best for us and what makes us happy." (R12)

"A grandmother prays and watches over you and she'd gift you of anything." (R1)

Furthermore, the movie itself breaks the boundaries of socio-linguistic diversity. Though the setting and the language are foreign, the image portrayed is not only contextual but universal and classical. In other words, the language of love is perceived to be borderless. Grandmothers, those of either Filipino or Korean descent, have been reported to be similar in ways, particularly in expressing love and care. These statements echo how love transcends culture and language.

"I think Korean and Filipino grandmothers all have in common: they always make you feel loved, they show affection, they always care for you, put your welfare first, and make sure you are warm and sound asleep at night, and when you wake up food is ready." (R12)

"The love of a grandmother has no boundary. Whatever nationality a grandmother may have --- Korean or Filipino --- they show the same love to their grandchildren. Love knows no boundaries after all." (R6)

"There is a universal language for grandmothers when it comes to their grandson/granddaughters and that is their unconditional love towards them." (R3)

"When I watched the film, I have memory recall of my own experiences of my Lola, the ever-loving and selfless Lola just like in the movie. I come to realize that there is no loving person as loving as she is. She can spoil because everything I want is given as much as she can." (R6)

As shown, there is no doubt that the kind of love offered by a grandmother is made special by her own ways of showing concern and affection to people around her, particularly to her grandchildren. No measurement can gauge the immense horizons of this affection. Her love is considered to be never-ending, selfless, and most especially relative. This is also the reason that the responses and claims under this theme are made stronger because of the personal experiences of graduate students. 


\section{A Brand of Fighting Spirit}

A lot of responses have affirmed that sacrifices made living with a grandmother are worthwhile experiences. These grandparents' contributions provide insightful life guidelines for parents and grandchildren. Implicitly, these create a figure of determination to live well and this is reflected in the main character. She is said to possess traits comparable to that of a parent: they are loving, caring, and understanding in one way or another.

"The grandmother in the movie is like some grandmothers and mothers in the Philippines. I actually likened her to my mother. My mother is very patient and she takes all of life's difficulties in stride." (R2)

The experiences of the participants also emphasize that grandmothers unintentionally create an unbreakable link to their grandchildren. The efforts of these people are appreciated by their grandchildren. The movie allows a participant to realize that grandparents' affection proceeds incomparable attachment.

"Most of the time, grandchildren will be attached to their grandmothers because of the love, care, and understanding that grandmothers have showered to them." (R8)

Furthermore, the grandmother may be old in terms of physique but her willingness to live her life to the fullest has made it clear that she has her own brand of fighting spirit. Her strength may not be demonstrated by physical characteristics, but it is done by her love and sacrifice. The polysemy of grandmothers' strength surpasses the corporal line. They go beyond their physical limitations especially in the absence of their grandchildren's parents. The participants point out that this kind of strength's universality exists even in the Philippines.

"Behind their withered looks and fragile frames, they still want to help around the house." (R2)

"Grandmothers in the Philippine setting also tend to sacrifice their needs just to show their love to their children and grandchildren. The grandmother is also very much willing to take care of the grandchildren in spite of old age." (R8)

"Grandmothers play a significant part in one's life. If in case parents are unable to take care of their kids, grandparents usually take their responsibilities." (R10)

An image of fortitude is also portrayed in the movie. The graduate students identify specific episodes in the film that manifest how a grandmother's fighting spirit has been proven to be resilient in all aspects. The character reveals unceasing patience, undying determination, undeniable influence, and unsurmountable tutelage to her grandchild's being and life. Thus, it has left a special message to graduate students on how to grow with precious experiences with a grandmother: to cherish and learn from it and be grateful for it. In other words, the action brought by affection leads to appreciation.

"Sang-woo, angry and confused by the unfamiliar environment, repeatedly rejected her attempts to please him. But her unconditional love slowly touches his heart. She is so giving and selfless." (R13)

"The grandmother is too old to walk from home to the market but it doesn't stop her to endure the pain and the heat of the sun. She is the type of 
Lola/grandmother that is too patient just to provide for her little one." (R6)

"We must learn to appreciate and never forget that what we have become today was partly because of their influence in our lives and how they are being there made the greatest difference." (R9)

"We have learned what's really important in life thanks to our parents/grandparents because they endured our constant dissatisfaction and nagging, and eventually imparted their insight and wisdom." (R13)

From these responses, it can be claimed that a grandmother is a woman who exhibits a solid spirit and strong personality. She carries with her a particular brand of fighting spirit anchored on selfless love that surely touches the heart of those around her. The overlapping connection among action, affection, and appreciation are revealed in this film as perceived by the graduate students.

\section{Unique Sense of Style}

Life with a grandmother is filled with episodes of sweet and love-filled memories. These may vary from one person's experience to another. As experiences may vary, the way one lives, such as those of grandmothers, also comes in diversity. They are said to show a unique sense of style when it comes to living one's life. As the participants emphasize, though grandmothers deal with life in varieties of the way such as in times of new life chapters and dilemmas, the love they show is unquestionable.

"Filipino grandparents also support their children until they also have their own family. The love and care are being extended to all new family members." (R1)

"Although the manner of expressing it differs, still it shows how deep, comforting, encouraging, and absolute the love of a grandmother is." (R3)

In general, no lives are the same. One has always a unique way to set phases in his or her line of life and a series of sacrifices. The same is true among grandmothers. They live and love in multiple avenues and these serve as a model of living to everybody. A grandmother's sacrifices inspire those people around her variously. Moreover, some responses affirm insights on becoming the best grandmother they can ever be, through their perceived patterns of inspirations. These insights are a grandmother's unappreciated subtle deeds with tremendous impacts. Her sacrifices are always remembered, Korean and Filipino grandmothers alike. Thus, as the participants realize, the norms of a grandmother's love are undeniably universal.

"Grandmothers can walk for miles, travel alone, sleep late at night, wake up just to feed or bath us, or even work just to pamper their grandchildren. We often neglect or take them for granted for their efforts and most of the time, we find it annoying but in reality, they always make sure that we are taken care of and shown the best that grandmothers can give." (R12)

"The movie portrayed the ideal grandmother that I wanted to have. Perhaps I could be like her to my grandchildren." (R17)

"If I will become a grandmother in the future, I hope and pray that God will give me to become the best grandmother ever." (R1) 
"In the Philippines, the similar characteristics of a grandmother are that of being simple, nurturing, and humble." (R4)

"While I was watching the movie, I felt a degree of sentimentality. I connected the sensation with my age and living together with my aging parents: witnessing my children closely interacting with them and seeing the difference of the dynamics of their involvement with that of the characters in the movie. I found it very touching." (R11)

"The grandmother only has what is essential and she is content with it and even shares the very little that she has. These characteristics are very similar to Filipino grandmothers, as I have experienced in my family and observed in other families." (R13)

Moreover, generally speaking, responses of graduate students point to an argument regarding Korean and Filipino grandmothers: similar characters and images that go beyond culture and language. They may have a different way of life, but their impact on a person's life is immense, meaningful, and relatively similar. As presented through the responses, they are perceived to be condoning of their grandchildren's attempt to go beyond rules but seen as loving and giving friends to them.

"The true essence and character of a grandmother are universal. It does not choose and limit cultures, race, educational attainment, personality, language, and spirituality/ religion." (R11)

"Grandmothers are the best buddies. They allow what the parents prohibit their children to do. They are the ones who show that love can be like that --it may have a positive or negative effect in the long run." (R6)
"Most grandmothers in Philippine culture tend to give more to their grandchildren that their own children." (R9)

Treatment comes in different modes depending on the persons whom one deals with and/or on what attitude an individual has; however, it seems common to grandmothers to treat their grandchildren in the nicest way possible. A grandmother's character is made special because of the way she treats her grandchildren. She is always ready to provide the needs of others. A parent may say "no", but a grandmother is always willing to say "yes" to whatever her grandchildren may ask.

"The grandmother is most likely very close to the grandson or granddaughter to the point of spoiling them as to their wants and caprices that parents do not want to provide." (R8)

"Grandmothers can be overprotective or spoiling the child to whatever toys, food, and needs." (R4)

"In the Philippines, grandmothers are very indulgent with their grandchildren to the point of spoiling them and rooting for them when they are scolded by their parents." (R2)

Life's journey with a grandmother leaves footprints that can never be forgotten. Her presence in one's life has made it clear that with a grandmother's love, nothing is impossible. Their ability to tolerate their grandchildren's misdeeds and their sense of modesty create a peculiar tag that suggests how great they are. Due to the memories created with a grandmother, her influence transcends even beyond the days of a life span. However, as perceived, these moments 
may be touching, but excruciating when they end.

"When my Lola (grandmother) died and left us, it hurts so much because I was so attached. When the pain subsided I have appreciated what she was doing for me. It was so amazing to journey with the kind of grandmother who was so hardworking and never left us alone." (R6)

"Her endless patience and humility were demonstrated when she doesn't scold her grandson Sangwoo. She allowed him to do anything and did not impose anything on his grandson." (R3)

"They are more patient with their grandchildren, and perhaps because the kids are not their primary responsibility anymore, they want the time spent with them pleasant." (R2)

Grandmothers, whether Korean or Filipino, exhibit images that reveal her unique sense of style. The movie has perfectly captured how people around a grandmother would agree about their experiences and feelings. A grandmother is similar to that of a mother in terms of love and sacrifice.

Moreover, based on the perception of the participants, the totality of a grandmother's image of selfless, unconditional, and passionate love is captured in the film on focus, in different angles of both universal and contextual realities.

"The images of a grandmother in the movie were quite similar to the images of Filipino grandmothers. Our grandmothers were like our mothers: loving, dedicated, forgiving, patient, always excited to help, more than willing to help. They don't expect anything in return, willing to sacrifice anything and everything to show love to their grandchildren." (R10)
"The grandmother has inspired me to love more unconditionally, to love beyond words, and to love eternity above all things on earth. All the happiness she brings cannot be bought by money nor can be exchanged to something in return." (R6)

"The grandmother shows an image of such a passionate and understanding person. She was passionate in the sense that despite the wrongdoings of her grandson, she persists to take care and understand his misbehavior." (R8)

\section{Conclusion}

The film "The Way Home" Jibeuro captures numerous images of a grandmother, as reported by Filipino graduate students with reference to their own personal experiences: unconditional and never-ending spring of love, a brand of fighting spirit, and unique sense of style.

The film depicts a different way of life compared to Koreans compared to Filipino culture and this puts a greater emphasis on bridging how a grandmother's life can be viewed across cultures: influential, colorful, and inspiring. A grandmother's love is incomparable as she serves as a source of affection. She sees the beauty in things and this is manifested by her untiring spirit and round-the-clock support. A grandmother is generous even up to the last piece of her material wealth.

The life of a grandmother is an evident example of sacrifice in the name of love. She looks tough and hardworking and her sacrifices are immeasurable. Despite old age, a grandmother is a symbol of gentle and strength ready to sacrifice in the name of her beloved. 


\section{References}

Ancho, Inero V. "Learning Korean as a Foreign Language: The Case of a Teacher Education Institution in the Philippines." Human Behavior, Development and Society 20, no. 2 (June 2019): 74-81.

Azhar, Kaukab Abid, Nayab Iqbal, and Mahvish Sohaib Khan. "Do I Talk Too Much in Class? A Quantitative Analysis of ESL Classroom Interaction." OKARA: Jurnal Bahasa dan Sastra 13, no. 2 (November 23, 2019): 193-202. https://doi.org/10.19105/ojbs.v13i2.2 491.

Boyd, Julia. "An Examination of Native Americans in Film and Rise of Native Filmmakers." The Elon Journal of Undergraduate Research in Communication 6, no. 1 (October 2014): 105-13.

Commission on Higher Education of Office of the Resident of the Republic of the Philippines. Implementing Guidelines in the Inclusion of Foreign Language as Electives, in the Curricula of Higher Education Programs, 23 Ched Memorandum Order (2010).

Darancık, Yasemin. "Students' Views on Language Skills in Foreign Language Teaching." International Education Studies 11, no. 7 (2018): 166-78.

https://doi.org/10.5539/ies.v11n7p16 6.

Demiroz, Hakan, and Savas Yesilyurt. "Effective Foreign Language Teaching: Perceptions of Prospective English Language Teachers." Universal Journal of Educational Research 3, no. 11 (2015): 862-70. https://doi.org/10.13189/ujer.2015.0 31112 .

İşcan, Adem. "Using Films in Vocabulary Teaching of Turkish as a Foreign Language." Journal of Education and Training Studies 5, no. 5 (May 2017): https://doi.org/10.11114/jets.v5i5.22 45.

Iwashita, Chieko. "Roles of Films and Television Dramas in International Tourism: The Case of Japanese Tourists to the UK." Journal of Travel \& Tourism Marketing 24, no. 2-3 (June 1, 2008): 139-51. https://doi.org/10.1080/1054840080 2092635.

Kondo, David, and Yang Ying Ling. "Strategies for Coping with Language Anxiety: The Case of Students of English In Japan." ELT Journal 58, no. 3 (July 2004): 25865.

https://doi.org/10.1093/elt/58.3.258.

Küçükler, Halil, and Abdullah Kodal. "Foreign Language Teaching in Over-Crowded Classes." English Language Teaching 12, no. 1 (2019): 169-75. https://doi.org/10.5539/elt.v12n1p16 9.

Lauzen, Martha, and David Dozier. "Maintaining the Double Standard: Portrayals of Age and Gender in Popular Films." Sex Roles 52 (April 1, 2005): 437-46. https://doi.org/10.1007/s11199-0053710-1.

Lee, Mina, Won Oh, and Kyung Lee. "North Korean Refugee Women's Consumption of South Korean TV Dramas and Movies." Asian Women 29 (December 1, 2013): 1-23.

Lewis, Kimberly Anne Brooks. "Adult Learners' Perceptions of the Significance of Culture in Foreign Language Teaching and Learning." Journal of Education and Training Studies 2, no. 2 (April 2014): 9-19. https://doi.org/10.11114/jets.v2i2.250.

Marwati, Sofia, and Gusdi Sastra. "Working Memory Role on Gender towards Language Transfer: Study of Neurolinguistics." OKARA: Jurnal Bahasa dan Sastra 13, no. 2 (November 23, 2019): 181-92. https://doi.org/10.19105/ojbs.v13i2.2 566. 
Merskin, Debra. "Reviving Lolita?: A Media Literacy Examination of Sexual Portrayals of Girls in Fashion Advertising." American Behavioral Scientist 48, no. 1 (September 2004): 119-29. https://doi.org/10.1177/0002764204 267257.

Stern, Susannah R. "Self-Absorbed, Dangerous, and Disengaged: What Popular Films Tell Us about Teenagers." Mass Communication and Society 8, no. 1 (February 1, 2005): 23-38. https://doi.org/10.1207/s15327825m cs0801_3.

Utama, Gina Nanda, and Rosaria Mita Amalia. "Negative Representation of Assad's Regime in CNN Online Articles." OKARA: Jurnal Bahasa dan Sastra 13, no. 1 (May 31, 2019): $\quad 1-16$. https://doi.org/10.19105/ojbs.v13i1.2 140.

Vaseghi, Reza, Effatdokht Ramezani, and Reza Gholami. "Language Learning Style Preference: A Theoretical and Empirical Study." Advances in Asian Social Sciences 2, no. 2 (2012): 441-51.

Vedishenkovaa, Marina V., and Anna Y. Mironinab. "The Methodology of Foreign Language Integrative Teaching at the Initial Stage of Interpreter Training." International Journal of Environmental \& Science Education 11, no. 8 (2016): 1975-88. https://doi.org/10.12973/ijese.2016.5 71a.

Wafi, Abdul. "Using Games to Improve Students' Active Involvement in the Learning of English Syntax at IAIN Madura: An Autonomous Learning." OKARA: Jurnal Bahasa dan Sastra 13, no. 1 (May 31, 2019): 107. https://doi.org/10.19105/ojbs.v13i1.2 256.

Woodrow, Lindy. "Motivation in Language Learning." In Essential Competencies for English-Medium University Teaching, by R. Breeze and C. Sancho, 235-48.
Educational Linguistics, 2017. https://link.springer.com/ content/pdf/10.1007\%2F978-3-31940956-6_16.pdf. 